Laser Chem., 1999, Vol. 19, pp. 133-139

Reprints available directly from the publisher Photocopying permitted by license only
(C) 1999 OPA (Overseas Publishers Association) N.V. Published by license under the Harwood Academic Publishers imprint, part of The Gordon and Breach Publishing Group.

\title{
TIME-RESOLVED INFRARED SPECTROSCOPY IN SUPERCRITICAL FLUIDS
}

\author{
MICHAEL W. GEORGE*, MARTYN POLIAKOFF, \\ XUE-ZHONG SUN and DAVID C. GRILLS \\ School of Chemistry, University of Nottingham, \\ Nottingham, England NG7 2RD
}

(Received 4 June 1997)

\begin{abstract}
We have used fast Time-resolved Infrared Spectroscopy (TRIR) to probe organometallic reactions in supercritical fluids on the nanosecond time-scale. This has allowed us to identify, for the first time in solution at room temperature, organometallic noble gas complexes which are formed following irradiation of metal carbonyls in supercritical noble gas solution. We have found that these complexes are surprisingly stable and have comparable reactivity to organometallic alkane complexes. We have also studied the coordination of $\mathrm{CO}_{2}$ to metal centres in supercritical $\mathrm{CO}_{2}\left(\mathrm{scCO}_{2}\right)$ and provide the first evidence for the formation and reactivity of $\eta^{1}-\mathrm{O}$ bound metal $\mathrm{CO}_{2}$ complexes in solution at or above room temperature.
\end{abstract}

Keywords: Time-resolved IR Spectroscopy; supercritical fluids; transition metal carbonyls

\section{INTRODUCTION}

Time-resolved Infrared spectroscopy (TRIR), a combination of UV flash photolysis and very fast IR spectroscopy (ns), has been outstandingly successful in identifying reactive intermediates [1] and excited states [2] of metal carbonyl complexes in solution and polymer films. We have demonstrated the potential of TRIR for the elucidation of photochemical reactions in supercritical fluids [3]. Supercritical

\footnotetext{
*Corresponding author. Fax: +44 1159513563 , e-mail: Mike.George@nottingham.ac.uk
} 
Fluids (SCFs) are curious hybrids of gases and liquids which offer intriguing possibilities for transient vibrational spectroscopy. A Fluid is said to be "supercritical" when its temperature and pressure exceed the temperature and pressure at the critical point $\left(T_{\mathrm{c}}\right.$ and $\left.P_{\mathrm{c}}\right)$. SCFs are unique solvents since their properties (viscosity, dielectric constant, diffusivity) vary with density which is a strong function of temperature and pressure [4]. The advantage of using TRIR to probe metal carbonyl reactions in supercritical fluids is that $\nu(\mathrm{C}-\mathrm{O})$ IR bands are relatively narrow so that several different species can be easily monitored. In this paper we review our recent results in the areas of organometallic noble gas complexes and activation of $\mathrm{CO}_{2}$.

\section{EXPERIMENTAL}

The Nottingham TRIR apparatus has been described in detail elsewhere [2]. Briefly, a pulsed Nd: YAG laser (Quanta-Ray GCR$11 ; 266 \mathrm{~nm}$ or $355 \mathrm{~nm}$ ), is used to initiate the photochemical reaction and a cw infrared source, (Mütek IR diode laser) monitors the changes in infrared transmission following the UV/visible pulse. IR spectra are built up on a "point-by-point" basis by repeating this measurement at different infrared frequencies. The stainless steel high pressure cells for supercritical TRIR have been described previously [4, 5]. All solutions were characterized by conventional FTIR prior to use.

\section{FORMATION AND REACTIVITY OF ORGANOMETALLIC NOBLE GAS COMPLEXES IN SOLUTION AT ROOM TEMPERATURE}

We have recently generated, for the first time, organometallic noble gas complexes in fluid solution at room temperature following irradiation of metal carbonyls in supercritical noble gas solution [6]. We were able to characterise $\mathrm{W}(\mathrm{CO})_{5}(\mathrm{Ar}), \mathrm{M}(\mathrm{CO})_{5}(\mathrm{Kr})$ and $\mathrm{M}(\mathrm{CO})_{5}(\mathrm{Xe})(M=\mathrm{Cr}$, Mo and $\mathrm{W})$, Scheme 1 .

By comparing the second-order rate constant for reaction of $\mathrm{M}(\mathrm{CO})_{5} L$ with $\mathrm{CO}$ in supercritical $L$ ( $L=\mathrm{Xe}, \mathrm{Kr}, \mathrm{Ar}$ (W only) and $\mathrm{CO}_{2}$ ), we were able to compare the reactivity of these noble gas species 


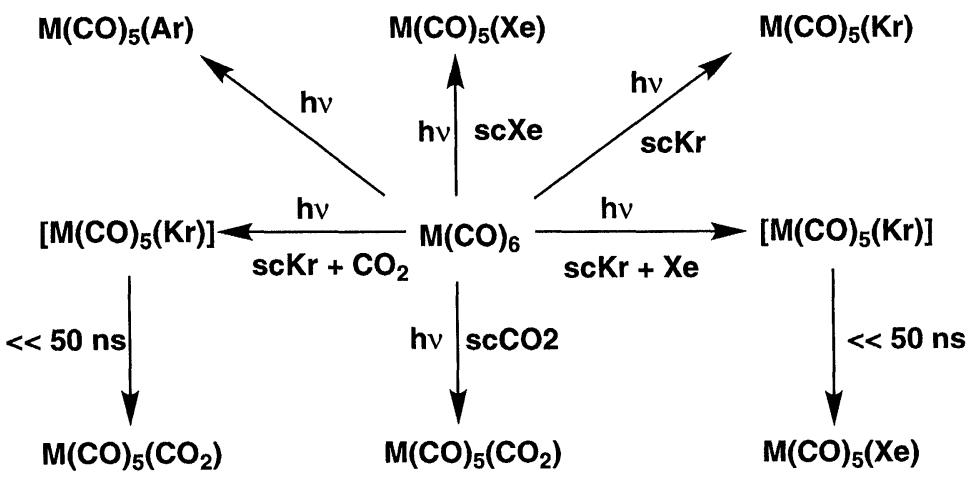

SCHEME 1 Showing the Group VI noble gas and $\mathrm{CO}_{2}$ complexes following photolysis of $\mathrm{M}(\mathrm{CO})_{6}(M=\mathrm{Cr}$, Mo and $\mathrm{W})$ in either supercritical noble gas or $\mathrm{CO}_{2}$ solution.

and found that $\mathrm{W}(\mathrm{CO})_{5}(\mathrm{Xe})$ was the least reactive species, Figure 2. We have undertaken a systematic study of the reactivity of metal carbonyl noble gas complexes and TRIR has proved a powerful tool for the characterisation of these complexes. A typical TRIR spectrum is shown in Figure 1 for the characterisation of $\left(\mathrm{CD}_{3}\right) \operatorname{Re}(\mathrm{CO})_{4}(\mathrm{Xe})$.

We have found that for a given $16 \mathrm{e}^{-}$fragment, the Xe complex is only ca. $\mathrm{x} 2$ more reactive than the corresponding alkane complex e.g., $\mathrm{W}(\mathrm{CO})_{5}(\mathrm{Xe}) / \mathrm{W}(\mathrm{CO})_{5}(n$-heptane $)$. We have recently shown [7] that $\mathrm{CpRe}(\mathrm{CO})_{2}(\mathrm{Xe})$ is surprisingly unreactive and is thermally more stable than all the reported organometallic alkane complexes except $\mathrm{CpRe}(\mathrm{CO})_{2}\left(n\right.$-heptane). Furthermore $\mathrm{CpRe}(\mathrm{CO})_{2}(\mathrm{Kr})$ is sufficiently stable to be detectable on the $100 \mathrm{~ns}$ timescale even in the presence of Xe. Figure 2 shows the relative reactivity of all the noble gas complexes we have observed in solution at room temperature.

\section{ACTIVATION OF $\mathrm{CO}_{2}$}

We have used TRIR to study the interaction of metal centres with $\mathrm{CO}_{2}$ which can co-ordinate terminally in three ways [9], Scheme 2.

$\eta^{1}-\mathrm{C}$ (I) and $\eta^{2}-\mathrm{CO}_{2}$ (II) complexes have been isolated with crystallographic confirmation of the coordination mode. By contrast, theoretical predictions of $\eta^{1}-\mathrm{O}$ complexes have only been supported by spectroscopic evidence from cryogenic matrices. We were able to 


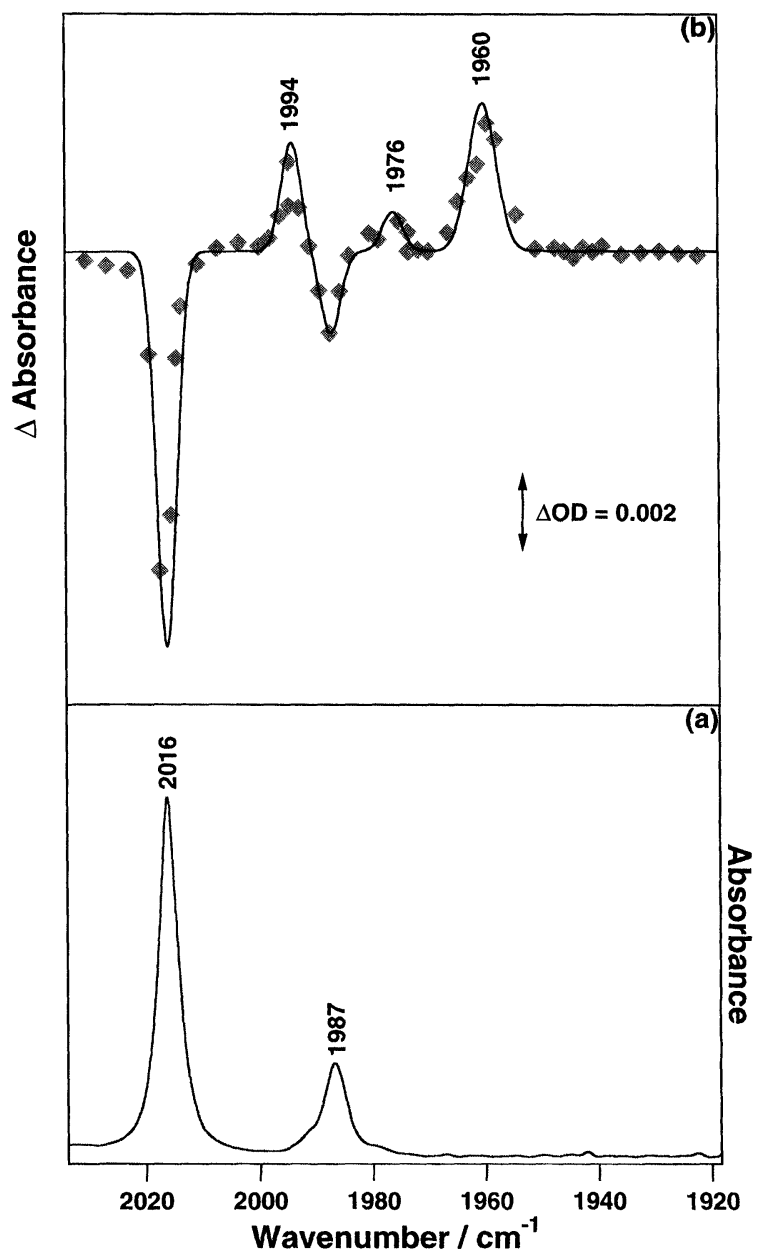

FIGURE 1 (a) The FTIR spectrum of $\left(\mathrm{CD}_{3}\right) \operatorname{Re}(\mathrm{CO})_{5}$ in supercritical Xe $(\mathrm{scXe})\left(25^{\circ} \mathrm{C}\right.$, $1350 \mathrm{psi})$ in the presence of CO (30 psi); (b) TRIR spectrum obtained $1 \mu \mathrm{s}$ following irradiation of this solution. The negative bands show depletion of parent and the positive bands at 1994,1976 and $1960 \mathrm{~cm}^{-1}$ are assigned to $\left(\mathrm{CD}_{3}\right) \operatorname{Re}(\mathrm{CO})_{4}(\mathrm{Xe})$ by comparison to the results in low temperature matrices [7].

obtain the first spectroscopic evidence, albeit circumstantial, for the $\eta^{1}$-O coordination of $\mathrm{CO}_{2}$ at room temperature, following $\mathrm{UV}$ irradiation of $\mathrm{W}(\mathrm{CO})_{6}$ in $\mathrm{scCO}_{2}$, Scheme 1 [5].

We have investigated both the steric and electronic factors which govern the coordination of $\mathrm{CO}_{2}$ to the metal centre. Using the $\nu(\mathrm{CO})$ 


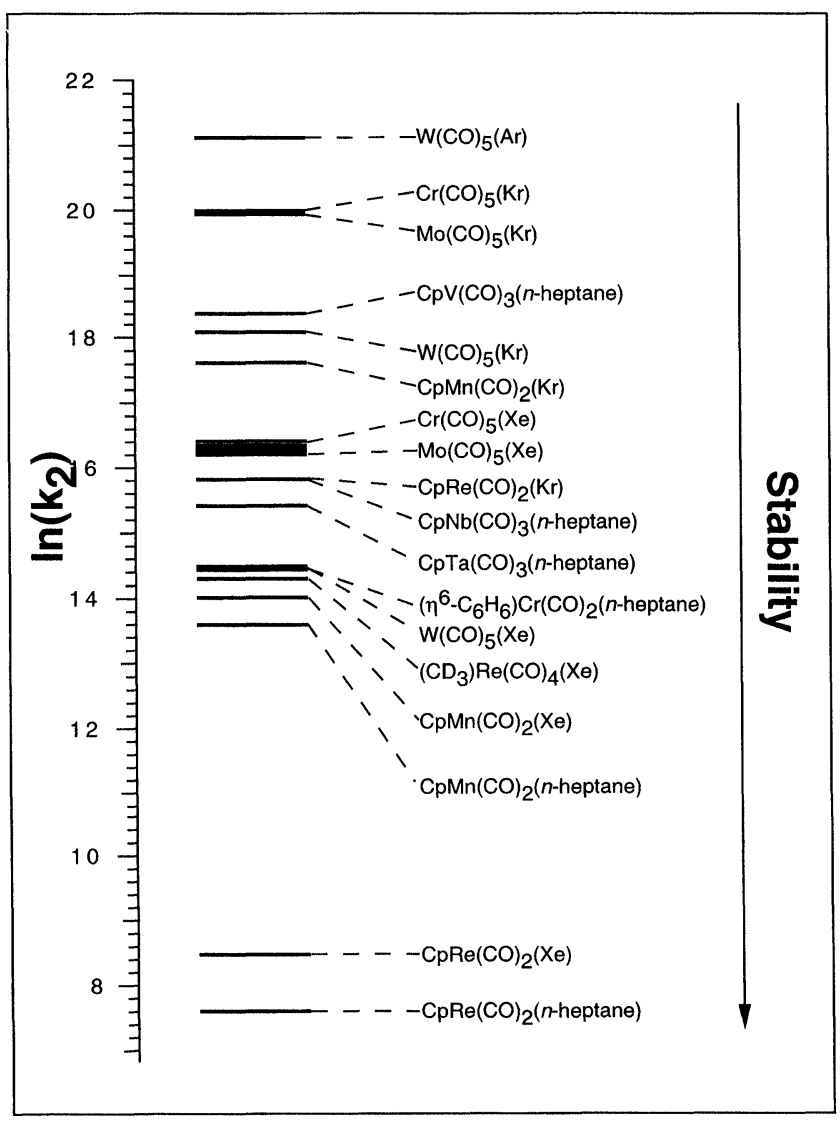

FIGURE 2 Plot of the second order rate constant for the reaction of the organometallic heptane, noble gas or $\mathrm{CO}_{2}$ complexes with $\mathrm{CO}$ in either heptane, scXe, $\mathrm{ScKr}, \mathrm{ScAr}$ or $\mathrm{scCO}_{2}$ solution at either $25^{\circ} \mathrm{C}$ ( $n$-heptane, scXe, $\mathrm{ScKr}$ or $\left.\mathrm{ScAr}\right)$ or $35^{\circ} \mathrm{C}$ $\left(\mathrm{scCO}_{2}\right)$ e.g., $\mathrm{L}_{m} \mathrm{M}(\mathrm{CO})_{x-1}(\mathrm{~L})+\mathrm{CO} \rightarrow \mathrm{L}_{m} \mathrm{M}(\mathrm{CO})_{x}+\mathrm{L}(\mathrm{L}=n$-heptane, $\mathrm{Xe}, \mathrm{Kr}, \mathrm{Ar}$ or $\mathrm{CO}_{2}$ ).<smiles>[N+]=COC(=O)C1OC1=O</smiles>
(I)

(II)

SCHEME 2 Showing the possible co-ordination modes of $\mathrm{CO}_{2}$ to a single metal centre. 
bands as an indication of the binding of $\mathrm{CO}_{2}$, we found [10] that $\mathrm{CpMn}(\mathrm{CO})_{2}\left(\mathrm{CO}_{2}\right)$ and $\mathrm{CpRe}(\mathrm{CO})_{2}\left(\mathrm{CO}_{2}\right)$ have different co-ordination modes of $\mathrm{CO}_{2}$, Figure 3. The downward shift in $\nu(\mathrm{CO})$ bands of $\mathrm{CpMn}(\mathrm{CO})_{2}\left(\mathrm{CO}_{2}\right)$ is suggestive of a $\eta^{1}-\mathrm{O} \mathrm{CO}_{2}$ complex but we observed that co-ordination of $\mathrm{CO}_{2}$ to the $\mathrm{CpRe}(\mathrm{CO})_{2}$ moiety resulted in oxidation of the Re centre, probably via $\eta^{1}-\mathrm{C}$ co-ordination of the $\mathrm{CO}_{2}$. All these assignments were based on the position of $\nu(\mathrm{C}-\mathrm{O})$ bands because our TRIR data were restricted to this region of the spectrum. We are extending these studies to cover IR regions where co-ordinated $\mathrm{CO}_{2}$ absorbs.

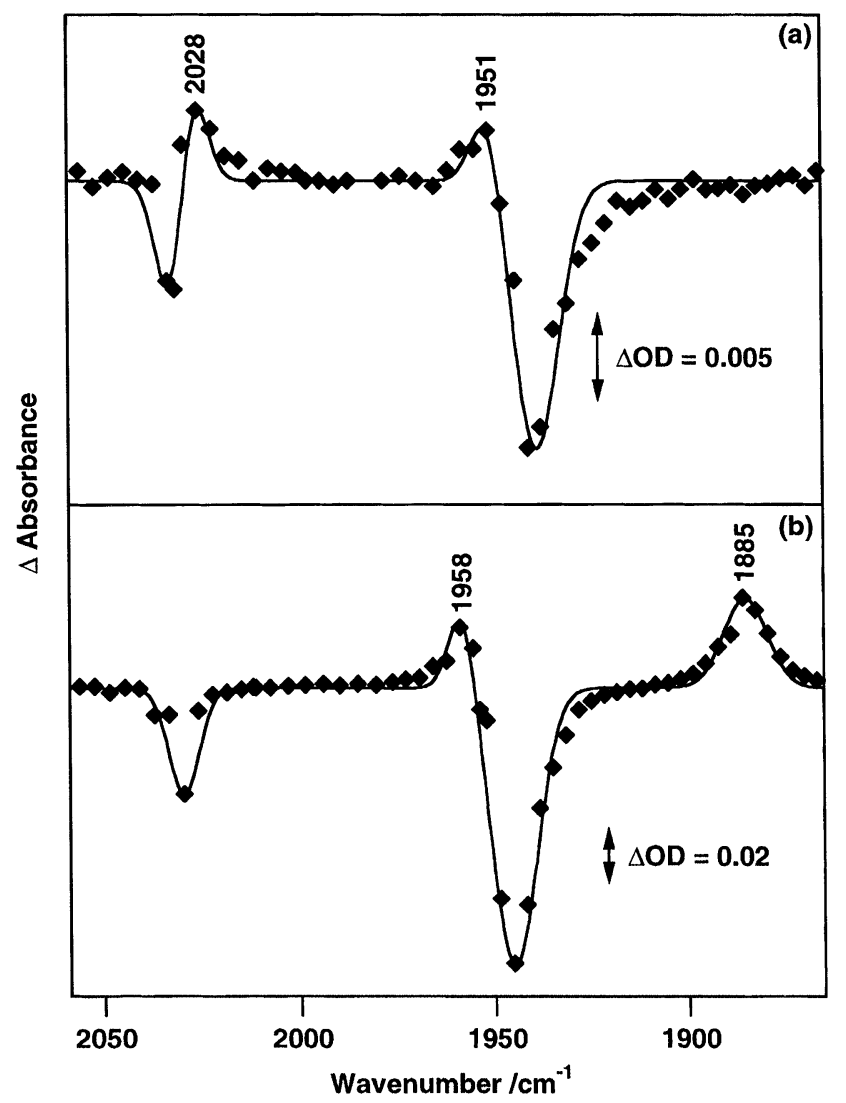

FIGURE 3 TRIR spectra obtained $1 \mu$ s after irradiation of (a) $\mathrm{CpRe}(\mathrm{CO})_{3}\left(\mathrm{Cp}=\eta^{5}\right.$ $\mathrm{C}_{5} \mathrm{H}_{5}$ ) and (b) $\mathrm{CpMn}(\mathrm{CO})_{3}$ in $\mathrm{scCO}_{2}$. 
We have demonstrated that TRIR is a powerful tool for studying organometallic noble gas and $\mathrm{CO}_{2}$ complexes in supercritical noble gas and $\mathrm{CO}_{2}$ solution.

\section{Acknowledgements}

We thank Professor J. J. Turner and Dr. S. M. Howdle for helpful discussions. We are grateful for the financial support of EPSRC Clean Technology Unit, the Royal Society, KC Wong Foundation, the Royal Academy of Engineering, the Government of the Isle of Man and the University of Nottingham. We thank Mr M. Guyler and $\mathrm{Mr}$ K. Stanley for their assistance.

\section{References}

[1] McHugh, M. A. and Krukonis, V. J. (1994). Supercritical Fluid Extraction: Principles and Practice; 2nd edition, (Butterworth-Heinemann, Boston).

[2] George, M. W., Poliakoff, M. and Turner, J. J. (1994). The Analyst, 119, 551.

[3] Turner, J. J., George, M. W., Johnson, F. P. A. and Westwell, J. R. (1993). Coord. Chem. Rev., 125, 101.

[4] Poliakoff, M., Howdle, S. M. and Jobling, M. and George, M. W. (1991). Second Int. Symposium on Supercritical Fluids, Ed., McHugh, M. A. (Johns Hopkins University, Baltimore, 189).

[5] Poliakoff, M., Howdle, S. M. and Kazarian, S. G. (1995). Angew. Chem. Int. Ed. Eng., 34, 27.

[6] Sun, X-Z., George, M. W., Kazarian, S. G., Nikiforov, S. M. and Poliakoff, M. (1996). J. Am. Chem. Soc., 118, 10525.

[7] Firth, S., Hortin-Mastin, A. S. L., Poliakoff, M., Turner, J. J., McKean, D. C., McQuillan, G. P. and Robertson, J. (1989). Organometallics, 8, 2876.

[8] Sun, X-Z., Grills, D. C., Nikiforov, S. M., Poliakoff, M. and George, M. W., J. Am. Chem. Soc., in press.

[9] Mascetti, J. and Tranquille, M. (1988). J. Phys. Chem., 92, 2177.

[10] Sun, X-Z, Grills, D. C., George, M. W., to be published. 